\title{
Will the end of bursaries lower student nurse applications to UK universities?
}

\author{
Emeritus Professor Alan Glasper, from the University of Southampton, discusses the recently launched \\ Government consultation on the future funding of nurse education and the abolition of student nurse bursaries
}

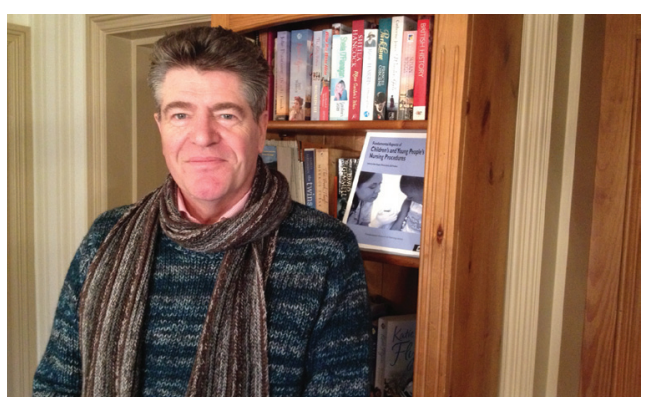

I

recently reported in the BJN the impact of the autumn public funding review for 2015 by Chancellor George Osborne. He announced the cessation of student nurse and other healthcare student bursaries in England, an initiative that is planned to save the Government up to $£ 800$ million a year (Glasper, 2016). The media have reported the disappointment of nurses and nursing unions such as the Royal College of Nursing (RCN). They believe that recruitment to the profession will be adversely affected by the introduction of loans for student nurses to attend university undergraduate courses.

Barring a reversal of the Government's decision, as of the academic year 2017/18 the current bursary given to student nurses in England will be replaced by loans to offset the $\mathcal{E}_{9} 9000$ per year university tuition fees and maintenance costs. The Guardian has reported that many student nurses will find it difficult to complete their training without the benefit of a bursary (Corry, 2016).

\section{Background}

Despite the strident pleas from student nurses to repeal the decision to abolish bursaries, it is interesting to note that in the 19th century, many student nurses funded their own training. An inspection of the London Hospital archives, for example, shows that in 1884 a class of paying probationers, for those who could afford to pay for their training, was introduced (AIM25, 2016). This would have resembled a means-tested system where those who could pay would do so. A probationer's training at the hospital lasted 2 years, the first year being concerned with theoretical knowledge and the second with practical skills. If successful in the examination at the end of this time, the qualified nurse was expected to serve for a further year. The archives report that training was later extended to 3 years and 1 year after qualification, which today would translate into a preceptorship year (AIM25, 2016).

Lorentzon (2003) highlights the attributes of 19th and early 20th century probationer nurses where character traits, as opposed to academic ability, were seen as more important. Perhaps this reflects Black's (2005) view of the lessons of 19th century nursing, which reinforces the principle that nurses must be central to the running of all aspects of hospitals. The founding of the NHS in 1948 heralded the introduction of equitable salaries for UK student nurses.

I vividly remember my first student nurse wage packet of $\mathcal{E} 18$ per month at the age of 17 when I started an orthopaedic nursing course of 20 months' duration in January 1969, before undertaking my state registration nurse training. Thankfully, my meagre wage included my subsistence, but not my accommodation, as I lived at home with my parents. I remember being somewhat perturbed when, at the age of 18 , the hospital started to deduct my salary to cover my pension contributions. A pension was the last thing on my mind as an 18 year-old.

Fortunately, however, unlike many of my peers in the 1970s, I made no attempt to withdraw my pension contributions to fund such things as an exotic post-qualifying holiday. This meant that by the age of 58 I had accrued 40 years of pensionable service on a final-salary scheme. Since the introduction of Project 2000 in the early 1990s, which heralded the introduction of the bursary rather than a salary, student nurses have been unable to begin paying into an NHS pension until after they have qualified.
This situation was predicated on the supernumerary full-time student status that Project 2000 conferred on applicants to NHS colleges of nursing, which were accredited by local universities or polytechnics. Subsequently, the NHS divested itself of its colleges and schools of nursing, and they were assimilated into the higher-education sector.

However, up until the introduction of the all-degree nursing courses that started in England in 2011, student nurses taking diploma-level courses leading to registration were entitled to a non-means-tested bursary (Glasper, 2016). Subsequent to the roll-out of the new nursing degree courses and the abolition of diploma-level courses, student nurses were still able to apply for means-tested bursaries (usually based on parental or spouse income), NHS grants of $£ 1000$, or reduced maintenance loans from Student Finance England. It is important to stress that it was the NHS in England that funded tuition fees, which in most universities are currently set at $£, 9000$ per year or $£ 27000$ over a typical 3 -year nursing course, leading to registration. The major benefit for current nursing students is that they do not have to repay them, unlike fellow university students taking traditional degree courses, who must repay student loans. This is all set to change and the media have been supportive of student nurses retaining the bursary system with, for example, The Guardian reporting that over 80000 healthcare students are currently being supported by the NHS to complete their training degrees (Corry, 2016).

However, there will be many nurse readers who have helped their own sons or daughters through university, and may perhaps feel that healthcare students should be treated no differently from undergraduates who, for example, have undertaken history degrees with a view to becoming teachers.

The Chancellor, in defending his decision to replace the bursaries with student loans, justifies it by emphasising that the bursary system 
has merely imposed a cap on student-nurse applications. He points out that over half of all applicants are not accepted for a university place anyway, leaving many hospitals to rely on filling nursing posts with agency/bank nurses or recruiting nurses from overseas (Sims, 2015).

However, it must be stressed that it was the same government that cut commissions in nurse-training places in many English universities as part of its drive to reduce costs to the Exchequer in the wake of the last financial crisis.

\section{The consultations on healthcare student funding}

It is because of the complexities involved that in April 2016 the Department of Health (DH) launched a consultation into how the changes to healthcare-student funding for degree places can be implemented (DH, 2016).

It is beyond the scope of this article to consider student funding for all healthcare professions, and information that is pertinent only to student nurse funding will be considered here. The DH believes that under the current funding arrangements, which are financed through the local education training boards, nearly two-thirds of people who apply to enter nurse training are not accepted. It is also the DH's belief that the new funding proposals will create many more training places for student nurses by 2020 , thus allowing universities who offer nursing courses to accept more suitably qualified applicants than they are currently able to do.

Some nurse teachers, however, are concerned that the tuition fees of $£, 9000$ per year may deter some nursing applicants, who may instead consider seeking access to professional nurse training through the apprenticeship schemes, which will give them 'nursing associate' status and whereby, for many, fees will be underwritten by NHS employers. Nursing associates will be able to continue to further education through either full degreelevel nurse apprenticeships or a shortened nursing degree courses at university (DH, 2015).

The DH consultation will run until 30 June and the department is urging interested organisations such as hospitals and members of the public to contribute to the consultation,

$\exists$ which is designed to examine how these changes to student nurse funding can best be implemented. Importantly, this includes consideration of opportunities for existing graduates in other subjects who apply for nurse training as a second degree to be eligible for a student loan. This notwithstanding, and irrespective of the Government's intentions, it is the role of Health Education England to work with institutes of higher education to ensure that only highly educated nursing graduates are recruited to the NHS to ensure that patients are given a safe and high-quality service. In parallel with this consultation, the Government aspires to increase the nursing workforce through the new nursing associate role, which will occupy a role once held by the enrolled nurse of yesteryear (Glasper, 2016).

These government reforms to the funding of nurse education are designed to address a number of factors caused by the current funding arrangements. The intended impact of these reforms will be, first, a significant increase, typically anticipated to be around $25 \%$ or more, in the living cost support available for full-time students. It will be funded through student loans, which for the period of their studentship would increase the amount of spending money they have during their undergraduate years. In this context, I interviewed two second-year student nurses about the proposed changes. One of them told me that she would not have considered entering nursing if it would result in her leaving university with a considerable debt; the other said that she would not mind being treated like other non-vocational students, although with the caveat that she would think it unfair if nurses had to work a 37.5hour week while on placement and have less holiday entitlement than, say, history students. This is because, unlike nursing students, history students do not have to complete $50 \%$ of their course in practice.

A second intended impact is a significant increase in the available supply of trained nurses, allowing more nursing students to study a degree and avoiding the situation where two-thirds of nursing applicants who apply for a place are rejected. However, this does not consider that the provision of a bursary may be a deciding factor for many applicants to enter nursing, especially mature students.

\section{Conclusion}

Starting in August 2017, nursing students will no longer have their course fees paid by the Government. Instead, they will be able to acquire a student loan and have access to the standard student support system provided by the Student Loans Company to cover the cost of their tuition fees, and means-tested support for their living costs. Importantly, and in a sea change for nursing students, the terms of repayment for the loan will be the same as for all other graduates. Currently, graduate repayment starts when a salary of $\mathcal{E} 21000$ is achieved, with repayments being $9 \%$ of income over $£ 21000$. The DH has estimated that a band-5 newly qualified staff nurse who earns $\mathcal{E}^{21700}$ per year will pay back $\mathcal{L}^{5}$.25 a month. If this loan is not repaid within 30 years, the balance is written off. It remains to be seen if this latest government initiative will result in an improvement in student nurse recruitment, or push some into the slower but less costly healthcare-associate route to firstlevel nursing. BJN

AIM25 (2016) Archives in London and the M25 area. Nursing Service records of the London Hospital. http:// tinyurl.com/jmvm94o (accessed 16 May 2016)

Black N (2005) Rise and demise of the hospital: a reappraisal of nursing. BMJ 331(7529): 1394-6

Corry H (2016) I knew nursing was what I had to do-my bursary made it possible. Guardian online, 10 February. http://tinyurl.com/zbm47pu (accessed 16 May 2016)

Department of Health (2015) Nursing associate role offers new route into nursing. http://tinyurl.com/hwgsbfe (accessed 16 May 2016)

Department of Health (2016) Changing how healthcare education is funded. http://tinyurl.com/zs5u $4 \mathrm{bt}$ (accessed 16 May 2016)

Glasper A (2016) Can a nursing associate role fill the void left by enrolled nurse training? Br J Nurs 25(3): 120-1

Lorentzon M (2003) Socialising nurse probationers in the late 19 th and early 20 th centuries. Nurse Educ Today 23(5) $325-31$

Sims A (2015) Autumn statement: Grants for student nurses to be scrapped and replaced with loans. Independent online, 25 November. http://tinyurl.com/pespx63 (accessed 16 May 2016)

\section{KEY POINTS}

- The Department of Health launched a consultation into healthcare student funding and how the changes to student funding for degree places can be implemented. The consultation will run until 30 June 2016

- The cessation of student nurses' and other healthcare students' bursaries in England could save the Government up to $£ 800$ million a year

- The Royal College of Nursing believes that recruitment to the nursing profession will be adversely affected by the introduction of loans for student nurses to attend university

- Some nurse teachers are concerned that tuition fees of $£ 9000$ per year may deter some applicants from nursing 